\title{
THE CIO SKILL SET, AND HOW CIOS OBTAINED THE SKILLS
}

\author{
Nicholas L Ball, Utah Valley University, nicholas.ball@uvu.edu \\ John E Anderson, Utah ValleyUniversity,janderson@uvu.edu
}

\begin{abstract}
The lead IS Manager role has changed over the last forty years from a technician managing a service function to a CIO executive with the potential to have a substantial strategic impact on the organization. However, unlike many of the other C-Level executives, the CIO manages a very technical staff, and there is still a controversy as to whether the CIO is half technician and half manager/strategist, or if the CIO has shed the technology role to be mostly manager/strategist. What is the skill set needed for the CIO role? Are these skills obtained through work experience prior to becoming CIO? Are these skills obtained through formal academic training? Are these skills obtained through CIO work experience? Through CIO responses to a survey we found that the highest rated CIO skills focus on strategic management, leadership, and communication. We also found that work experience both prior to and after becoming $\mathrm{CIO}$ is the most important source of CIO skills rather than formal education. Future research should examine improvements in the design of educational programs to support the career paths of those who wish to become CIOs.
\end{abstract}

Keywords: CIO, Chief Information Officer, CIO Skill Set, CIO Education

\section{INTRODUCTION}

Chief Information Officer (CIO) research has been performed for over forty years with many interesting articles and findings. The genesis article is probably B. Ives and M. Olson's 1981 MIS Quarterly article "Manager of Technician? The Nature of the Information Systems Manager's Job." They found that the IS Manager evolved from a technician managing a relatively unimportant service function in the 1960s to a vice presidential-level general manager of a department with substantial organizational impact by 1981 . They looked at daily activities, and especially at the nature of oral contacts that constitute $76 \%$ of their daily tasks. $54 \%$ of the subjects of the message units were related to general administration and operations. Interpersonal and motivational skills are relied on. The IS manager was surrounded by technical specialists who provided expertise as required. Rather than focus on day-to-day operations the IS manager spent more time planning IS strategy and human resource concerns.

As a follow-on study, a 1992 MIS Quarterly article "Executive or Functional Manager? The Nature of the CIO's Job" C. Stephens, W. Ledbetter, A. Mitra, and N. Ford looked at the role of the CIO, and how this role is different from the MIS manager. The CIO role was meant to bridge the gap between the organization's strategy and its use of information technology. They found that the CIO operates as an executive rather than a functional manager. CIOs participate in strategy planning acting as a bridge between IT and functional and external entities. Important factors for CIO success were resource allocation authority and level of peer acceptance.

There have been many articles discussing the CIO role (Grover, 1993; Karlsen, et al., 2002; Sojer, et al., 2006) and how this role has changed over time (Benjamin, et al., 1985). Some argue that the CIO is actually more of a technical manager than other executives are, while others conclude that the CIO is more of a strategic executive. Hunter (2010) pointed out that $\mathrm{CIO}$ success relies largely on shared understanding and agreement on role expectations between the $\mathrm{CIO}$ and senior management influenced by corporate culture. Peppard (2010) noted that the CIO role had changed from the strategist-bridge function to a new mandate of finding ways IT can change the company, a broader role of business transformation and innovation.

Other studies have focused on the competencies or skills sets that CIOs possess and how these competencies impact their organizations (Blaskovich and Mintchik, 2011). Allison (2010) argues that the changing role of the CIO will require that $\mathrm{CIO}$ skill sets will need to expand over time. 


\section{Issues in Information Systems \\ Volume 18, Issue 1, pp. 31-43, 2017}

Peppard also pointed out that, in 2010, the dominant point of view was that CIOs lack leadership skills, don't participate in strategy-making, have little credibility with their colleagues, are seen as not having built relationships at appropriate levels, and are deficient in communication and influencing skills. While conducting interviews, Peppard found that there is significant confusion about the role of CIO and what it means to be a CIO. However, Peppard also found that the CIO is first and foremost a business leader. Therefore it is more important that a CIO has a business perspective than a technical perspective. The competencies most important to CIO success were: leadership, vision, strategic thinking, relationship building, diplomacy, deliverer, and reader of the market. Peppard noted many examples of IT Managers who were promoted to CIO and failing because of lack of these business skills. He also found that the IT savviness of the CEO and senior leadership along with a good CIO are important to realizing the value of IT in organizations.

Spitze and Lee in their 2012 California Management Review article "The Renaissance CIO Project: The Invisible Factors of Extraordinary Success" found that the three most important success factors of a CIO were that CIOs must be: life-long learners, must be able to build and motivate cross-functional teams marshalling collective intelligence, and must be able to conceive and implement a customer-facing game-changing project. These are all business skills not computer technology related skills.

Hutter and Riedl (2017) synthesized the results of 98 studies over the past thirty years of CIO role research and presented a model of six roles of an effective CIO: Technology Provider, Strategic Supporter, Business Thinker, Innovation Driver, Integration Advisor, and Relationship Manager. It is interesting to note that only two out of the six roles is technical, while four are business roles.

In this study we examine the skill set of the CIO. Specifically, our research questions are: What is the skill set needed for the CIO role? Are these skills obtained through work experience prior to becoming CIO, through formal academic training, or through $\mathrm{CIO}$ work experience? The study is motived by our desire to examine the curriculum of a graduate IS program to determine if it might be tailored to help students obtain skills necessary for eventually becoming CIO. We recognize that becoming the most senior IS executive of a large company requires extensive work experience. As part of this study, we hope to identify the skills needed to become CIO as well determine which of those skills might be obtained as part of an individual's educational background. We believe that the results of this study will be interesting to those who hope to eventually become CIO and educators who want to adjust their curriculum to help students start on the path to becoming CIO.

\section{RESEARCH METHODOLOGY}

A survey was mailed to 2754 CIOs that came from an online database that listed corporate CIOs and were chosen based on company sales. The survey was mailed to all CIOs listed in the database whose companies exceeded $\$ 100,000,000$ in annual sales. Respondents had the option to record their responses on a paper survey or enter them at a custom website created for the study. Those who opted to complete the paper form of the survey could return their responses using a postage-paid, preaddressed envelop. 233 usable responses were returned for a response rate of $8.5 \%$. Descriptive statistics were utilized to explore the education, skills, and previous position of the CIOs. The 22 skills examined were derived from the ACM MSIS model curriculum.

\section{RESULTS}

The responses for the skill questions of the survey were analyzed using Microsoft Excel, which was also used to create the tables and charts presented in this paper. The results of the study are presented below. Because they skewed to the right we reported the median. In the graphs that follow we also sorted by mean within median. 


\begin{tabular}{|c|c|c|c|c|c|c|c|c|}
\hline \multicolumn{9}{|c|}{ Importance of Skill to CIO Role } \\
\hline Skill & Mean & Median & Mode & Min & Max & StDev & Skew & MgtVsTech \\
\hline Leadership/Teamwork & 4.5 & 5 & 5 & 0.0 & 5.0 & 1.3 & -3.08 & Mgt \\
\hline Bus Comm & 4.4 & 5 & 5 & 0.0 & 5.0 & 1.3 & -2.87 & Mgt \\
\hline Interpersonal Comm & 4.4 & 5 & 5 & 0.0 & 5.0 & 1.2 & -2.85 & Mgt \\
\hline Strategic IS Planning & 4.4 & 5 & 5 & 0.0 & 5.0 & 1.3 & -2.68 & Mgt \\
\hline Creativity/ProbSolv & 4.3 & 5 & 5 & 0.0 & 5.0 & 1.3 & -2.53 & Mgt \\
\hline Org Dev & 4.0 & 4 & 5 & 0.0 & 5.0 & 1.3 & -1.93 & Mgt \\
\hline Business Analysis & 4.0 & 4 & 5 & 0.0 & 5.0 & 1.3 & -1.94 & Mgt \\
\hline Strategic Bus Planning & 4.0 & 4 & 5 & 0.0 & 5.0 & 1.3 & -1.99 & Mgt \\
\hline Project Mgt & 4.0 & 4 & 5 & 0.0 & 5.0 & 1.3 & -2.01 & Mgt \\
\hline Change Mgt & 4.0 & 4 & 4 & 0.0 & 5.0 & 1.3 & -1.89 & Mgt \\
\hline Integration Mgt & 3.5 & 4 & 4 & 0.0 & 5.0 & 1.2 & -1.54 & Tech \\
\hline Acctg/Fin Mgt & 3.3 & 4 & 4 & 0.0 & 5.0 & 1.2 & -1.54 & Mgt \\
\hline HR Mgt & 3.3 & 3 & 4 & 0.0 & 5.0 & 1.2 & -1.00 & Mgt \\
\hline Security Mgt/Imp & 3.3 & 3 & 3 & 0.0 & 5.0 & 1.2 & -1.17 & Tech \\
\hline Infrastructure Mgt & 3.3 & 3 & 4 & 0.0 & 5.0 & 1.2 & -1.31 & Tech \\
\hline ERP Imp/Mgt & 3.1 & 3 & 3 & 0.0 & 5.0 & 1.3 & -0.83 & Tech \\
\hline App Dev & 3.0 & 3 & 4 & 0.0 & 5.0 & 1.3 & -0.59 & Tech \\
\hline $\mathrm{Opr} /$ Logitics Mgt & 3.0 & 3 & 3 & 0.0 & 5.0 & 1.2 & -0.79 & Mgt \\
\hline CRM Imp/Mgt & 2.9 & 3 & 3 & 0.0 & 5.0 & 1.2 & -0.74 & Tech \\
\hline Mkt Mgt & 2.7 & 3 & 3 & 0.0 & 5.0 & 1.1 & -0.85 & Mgt \\
\hline DB Design/Mgt & 2.6 & 3 & 3 & 0.0 & 5.0 & 1.2 & -0.44 & Tech \\
\hline \multicolumn{9}{|c|}{ Skill obtained through Prior Word Experience before becoming CIO } \\
\hline Skill & Mean & Median & Mode & Min & Max & StDev & Skew & MgtVsTech \\
\hline Leadership/Teamwork & 4.3 & 5 & 5 & 0.0 & 5.0 & 1.2 & -2.67 & Mgt \\
\hline Creativity/ProbSolv & 4.3 & 5 & 5 & 0.0 & 5.0 & 1.3 & -2.48 & Mgt \\
\hline Strategic IS Planning & 4.2 & 5 & 5 & 0.0 & 5.0 & 1.3 & -2.35 & Mgt \\
\hline Bus Comm & 4.2 & 5 & 5 & 0.0 & 5.0 & 1.2 & -2.43 & Mgt \\
\hline Interpersonal Comm & 4.2 & 5 & 5 & 0.0 & 5.0 & 1.2 & -2.44 & Mgt \\
\hline Business Analysis & 4.1 & 4 & 5 & 0.0 & 5.0 & 1.3 & -2.05 & Mgt \\
\hline Project Mgt & 4.0 & 4 & 5 & 0.0 & 5.0 & 1.3 & -1.79 & Mgt \\
\hline Org Dev & 3.9 & 4 & 5 & 0.0 & 5.0 & 1.3 & -1.72 & Mgt \\
\hline Strategic Bus Planning & 3.9 & 4 & 4 & 0.0 & 5.0 & 1.3 & -1.81 & Mgt \\
\hline Change Mgt & 3.8 & 4 & 4 & 0.0 & 5.0 & 1.3 & -1.67 & Mgt \\
\hline Acctg/Fin Mgt & 3.6 & 4 & 4 & 0.0 & 5.0 & 1.3 & -1.29 & Mgt \\
\hline Integration Mgt & 3.4 & 4 & 4 & 0.0 & 5.0 & 1.4 & -1.16 & Tech \\
\hline HR Mgt & 3.3 & 3 & 4 & 0.0 & 5.0 & 1.3 & -0.96 & Mgt \\
\hline ERP Imp/Mgt & 3.2 & 3 & 4 & 0.0 & 5.0 & 1.4 & -0.66 & Tech \\
\hline Infrastructure Mgt & 3.2 & 3 & 4 & 0.0 & 5.0 & 1.3 & -0.79 & Tech \\
\hline App Dev & 3.1 & 3 & 4 & 0.0 & 5.0 & 1.5 & -0.50 & Tech \\
\hline Opr/Logitics Mgt & 3.0 & 3 & 3 & 0.0 & 5.0 & 1.3 & -0.65 & Mgt \\
\hline
\end{tabular}




\begin{tabular}{|c|c|c|c|c|c|c|c|c|}
\hline Security Mgt/Imp & 3.0 & 3 & 3 & 0.0 & 5.0 & 1.2 & -0.81 & Tech \\
\hline CRM Imp/Mgt & 2.8 & 3 & 3 & 0.0 & 5.0 & 1.3 & -0.51 & Tech \\
\hline Mkt Mgt & 2.8 & 3 & 3 & 0.0 & 5.0 & 1.2 & -0.55 & Mgt \\
\hline DB Design/Mgt & 2.5 & 3 & 3 & 0.0 & 5.0 & 1.3 & -0.08 & Tech \\
\hline \multicolumn{9}{|c|}{ Skill obtained through Academic Training } \\
\hline Skill & Mean & Median & Mode & Min & Max & StDev & Skew & MgtVsTech \\
\hline Bus Comm & 3.1 & 3 & 4 & 0.0 & 5.0 & 1.4 & -0.71 & Mgt \\
\hline Acctg/Fin Mgt & 3.0 & 3 & 3 & 0.0 & 5.0 & 1.4 & -0.41 & Mgt \\
\hline Business Analysis & 2.7 & 3 & 3 & 0.0 & 5.0 & 1.4 & -0.29 & Mgt \\
\hline Creativity/ProbSolv & 2.7 & 3 & 3 & 0.0 & 5.0 & 1.4 & -0.19 & Mgt \\
\hline Leadership/Teamwork & 2.7 & 3 & 3 & 0.0 & 5.0 & 1.4 & -0.24 & Mgt \\
\hline Interpersonal Comm & 2.5 & 3 & 3 & 0.0 & 5.0 & 1.3 & -0.15 & Mgt \\
\hline Strategic Bus Planning & 2.4 & 2 & 3 & 0.0 & 5.0 & 1.3 & 0.06 & Mgt \\
\hline App Dev & 2.4 & 2 & 1 & 0.0 & 5.0 & 1.4 & 0.17 & Tech \\
\hline Project Mgt & 2.4 & 2 & 3 & 0.0 & 5.0 & 1.3 & 0.03 & Mgt \\
\hline Org Dev & 2.3 & 2 & 3 & 0.0 & 5.0 & 1.3 & 0.09 & Mgt \\
\hline DB Design/Mgt & 2.1 & 2 & 1 & 0.0 & 5.0 & 1.2 & 0.33 & Tech \\
\hline Mkt Mgt & 2.0 & 2 & 1 & 0.0 & 5.0 & 1.1 & 0.24 & Mgt \\
\hline Strategic IS Planning & 1.9 & 2 & 1 & 0.0 & 5.0 & 1.1 & 0.51 & Mgt \\
\hline HR Mgt & 1.9 & 2 & 1 & 0.0 & 5.0 & 1.1 & 0.52 & Mgt \\
\hline Opr/Logitics Mgt & 1.8 & 2 & 1 & 0.0 & 5.0 & 1.1 & 0.65 & Mgt \\
\hline Change Mgt & 1.8 & 2 & 1 & 0.0 & 5.0 & 1.1 & 0.62 & Mgt \\
\hline Integration Mgt & 1.7 & 1 & 1 & 0.0 & 5.0 & 1.0 & 0.77 & Tech \\
\hline Infrastructure Mgt & 1.6 & 1 & 1 & 0.0 & 5.0 & 1.0 & 0.79 & Tech \\
\hline Security Mgt/Imp & 1.6 & 1 & 1 & 0.0 & 5.0 & 0.9 & 0.80 & Tech \\
\hline ERP Imp/Mgt & 1.4 & 1 & 1 & 0.0 & 5.0 & 0.9 & 1.26 & Tech \\
\hline CRM Imp/Mgt & 1.3 & 1 & 1 & 0.0 & 4.0 & 0.8 & 1.21 & Tech \\
\hline \multicolumn{9}{|c|}{ Skill obtained through work experience as CIO } \\
\hline Skill & Mean & Median & Mode & Min & Max & StDev & Skew & MgtVsTech \\
\hline Leadership/Teamwork & 4.4 & 5 & 5 & 0.0 & 5.0 & 1.3 & -2.71 & Mgt \\
\hline Creativity/ProbSolv & 4.3 & 5 & 5 & 0.0 & 5.0 & 1.3 & -2.49 & Mgt \\
\hline Bus Comm & 4.3 & 5 & 5 & 0.0 & 5.0 & 1.3 & -2.51 & Mgt \\
\hline Interpersonal Comm & 4.2 & 5 & 5 & 0.0 & 5.0 & 1.2 & -2.47 & Mgt \\
\hline Project Mgt & 4.2 & 5 & 5 & 0.0 & 5.0 & 1.3 & -2.18 & Mgt \\
\hline Strategic IS Planning & 4.2 & 5 & 5 & 0.0 & 5.0 & 1.3 & -2.25 & Mgt \\
\hline Business Analysis & 4.1 & 4 & 5 & 0.0 & 5.0 & 1.3 & -2.12 & Mgt \\
\hline Strategic Bus Planning & 4.0 & 4 & 5 & 0.0 & 5.0 & 1.3 & -1.92 & Mgt \\
\hline Org Dev & 3.9 & 4 & 5 & 0.0 & 5.0 & 1.3 & -1.62 & Mgt \\
\hline Change Mgt & 3.9 & 4 & 4 & 0.0 & 5.0 & 1.3 & -1.76 & Mgt \\
\hline Integration Mgt & 3.7 & 4 & 4 & 0.0 & 5.0 & 1.3 & -1.52 & Tech \\
\hline Infrastructure Mgt & 3.6 & 4 & 4 & 0.0 & 5.0 & 1.3 & -1.28 & Tech \\
\hline App Dev & 3.6 & 4 & 5 & 0.0 & 5.0 & 1.5 & -0.92 & Tech \\
\hline
\end{tabular}




\begin{tabular}{lllllllll}
\hline Acctg/Fin Mgt & 3.5 & 4 & 4 & 0.0 & 5.0 & 1.3 & -1.19 & Mgt \\
\hline HR Mgt & 3.4 & 4 & 4 & 0.0 & 5.0 & 1.4 & -0.96 & Mgt \\
\hline ERP Imp/Mgt & 3.3 & 4 & 5 & 0.0 & 5.0 & 1.6 & -0.61 & Tech \\
\hline Security Mgt/Imp & 3.2 & 3 & 3 & 0.0 & 5.0 & 1.3 & -0.90 & Tech \\
\hline DB Design/Mgt & 3.0 & 3 & 3 & 0.0 & 5.0 & 1.4 & -0.36 & Tech \\
\hline Opr/Logitics Mgt & 2.9 & 3 & 4 & 0.0 & 5.0 & 1.5 & -0.41 & Mgt \\
\hline CRM Imp/Mgt & 2.9 & 3 & 3 & 0.0 & 5.0 & 1.4 & -0.41 & Tech \\
\hline Mkt Mgt & 2.8 & 3 & 3 & 0.0 & 5.0 & 1.2 & -0.59 & Mgt \\
\hline
\end{tabular}

\section{Importance of Skills to the CIO Role}

The CIOs rating of the importance of skills formed three clusters with scores of 5, 4 and 3 . The skills deemed most indispensable were: leadership/teamwork, business communication, interpersonal communication, strategic IS planning, and creativity/problem solving. The second skill cluster was composed of: organizational development, business analysis, strategic business planning, project management, change management, integration management, and accounting/financial management. The cluster made up of the least important skills included: human resource management, security management/implementation, infrastructure management, ERP implementation/management, application development, operations/logistics management, CRM implementation/management, marketing management, database design/management.

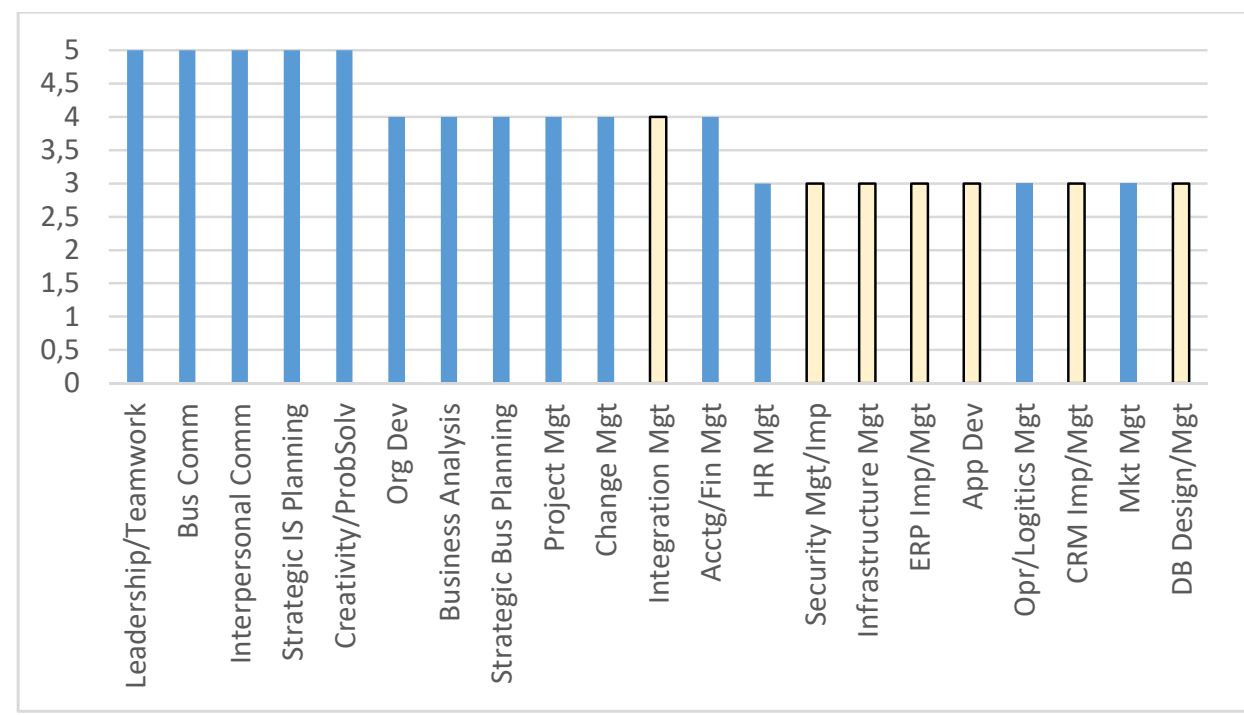

Figure 1. Median of Importance of Skill to CIO Role

\section{Prior work experience as a factor is obtaining skills important to the CIO Role}

The CIOs rating of whether they learned skills through prior experience formed three clusters with scores of 5, 4 and 3 . The skills most learned through prior work experience were: leadership/teamwork, creativity/problem solving, strategic IS planning, business communication, and interpersonal communication. This cluster is similar to the first cluster in the preceding section. The second skill cluster was composed of: business analysis, project management, organizational development, strategic business planning, change management, accounting/financial management, and integration management. This cluster is similar to the second cluster in the preceding section. The cluster made up of the skills least learned through prior work experience included: human resource management, ERP implementation/management, infrastructure management, application development, operations/logistics management, security management/implementation, CRM implementation/management, marketing management, and database 


\section{Issues in Information Systems \\ Volume 18, Issue 1, pp. 31-43, 2017}

design/management. Interestingly all of the clusters of the most important skills for the CIO role and whether respondent learned these skills through prior work experience are comprised of the same skills.

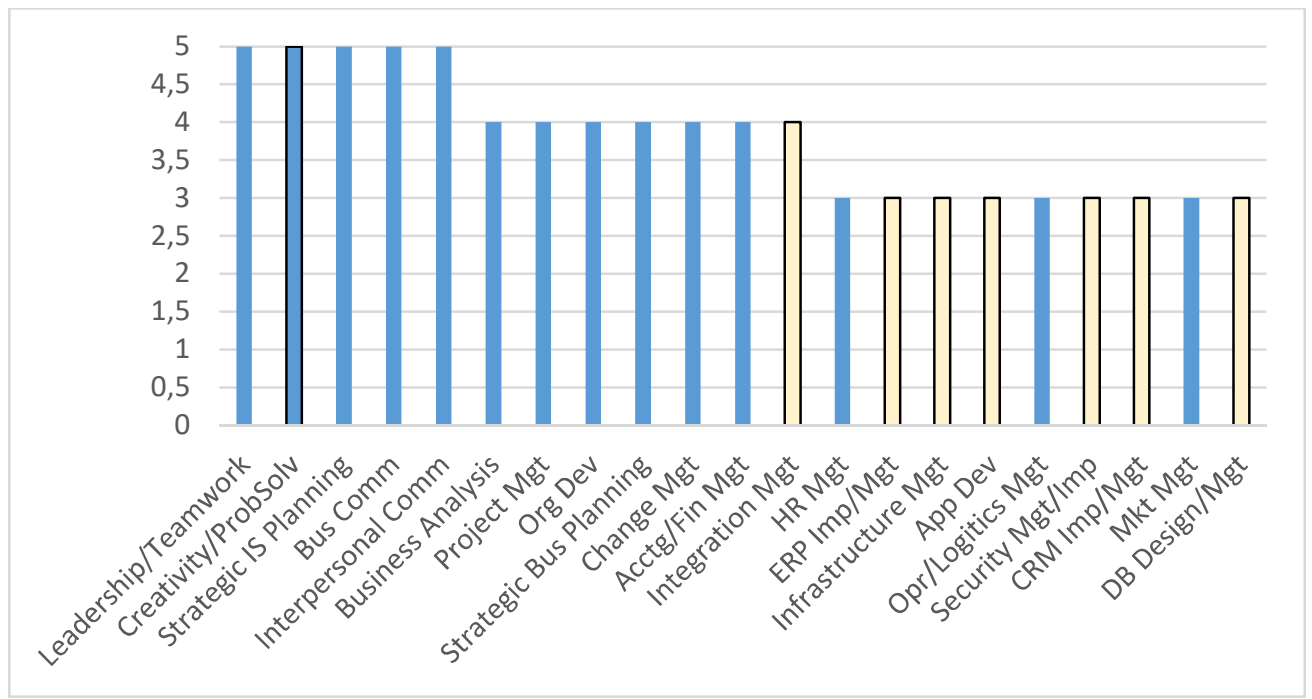

Figure 2. Median of Work Experience Prior to Becoming CIO

\section{Skills obtained through Academic training}

The CIOs rating of whether they learned skills through academic training formed three clusters with scores of 3, 2 and 1 (rather than 5, 4, 3 in the above two sections). The anchor points for the question were: little - moderate - extensive. It is interesting that no skills were learned extensively through academic training. The skills learned with the highest rating of moderate through academic training were: business communication, accounting/financial management, business analysis, creativity/problem solving, leadership/teamwork, and interpersonal communication. This cluster is quite different than the first clusters in the preceding sections. The second skill cluster was composed of: strategic business planning, application development, project management, organizational development, database design/management, marketing management, strategic IS planning, human resource management, operations/logistics management, and change management. This cluster is different than the second cluster in the preceding sections. The cluster made up of the skills least learned through academic training included: integration management, infrastructure management, security management/implementation, ERP implementation/management, and CRM implementation/management. Interestingly these three clusters are quite different than the clusters above of the most important skills for the CIO role and whether respondent learned these skills through prior work experience. 


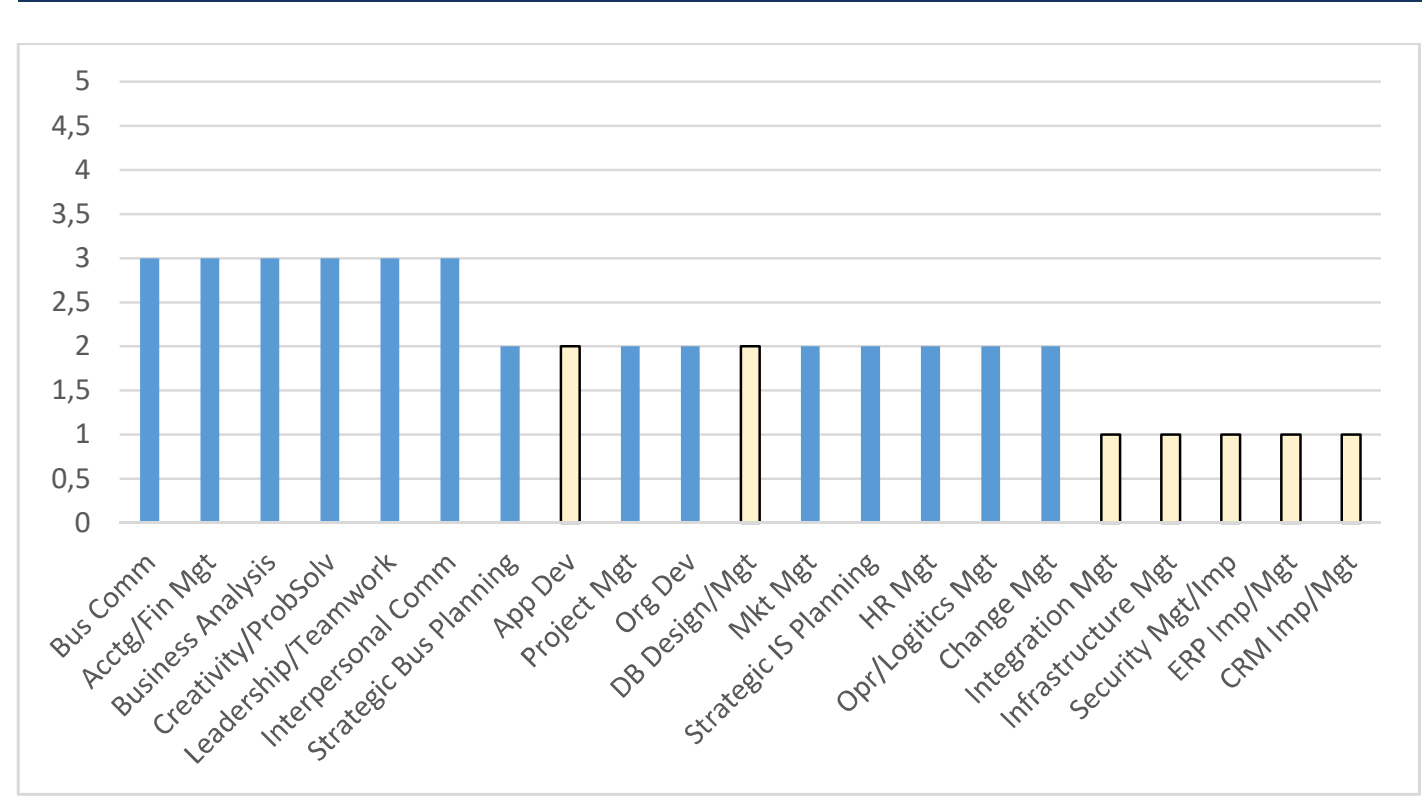

Figure 3. Median of Skills obtained through Academic Training

\section{Work experience (as a CIO) as a factor for obtaining skills important to the CIO Role}

The CIOs rating of whether they learned skills through work experience as a CIO formed three clusters with scores of 5, 4 and 3. The skills most learned through work experience were: leadership/teamwork, creativity/problem solving, business communication, interpersonal communication, project management, and strategic IS planning. This cluster is similar to the first clusters in the first two sections. The single exception is the addition of project management to the cluster, so that it includes six skills instead of five. The second skill cluster was composed of: business analysis, strategic business planning, organizational development, change management, integration management, infrastructure management, application development, accounting/financial management, human resource management, and ERP implementation/management. This cluster is different from the second cluster in the preceding first two sections in that the size of the cluster increased from seven to ten skills with the addition of infrastructure management, application development, and ERP implementation/management. The cluster made up of the skills least learned through work experience as a CIO included: security management/implementation, database design/management, operations/logistics management, CRM implementation/management, and marketing management. 


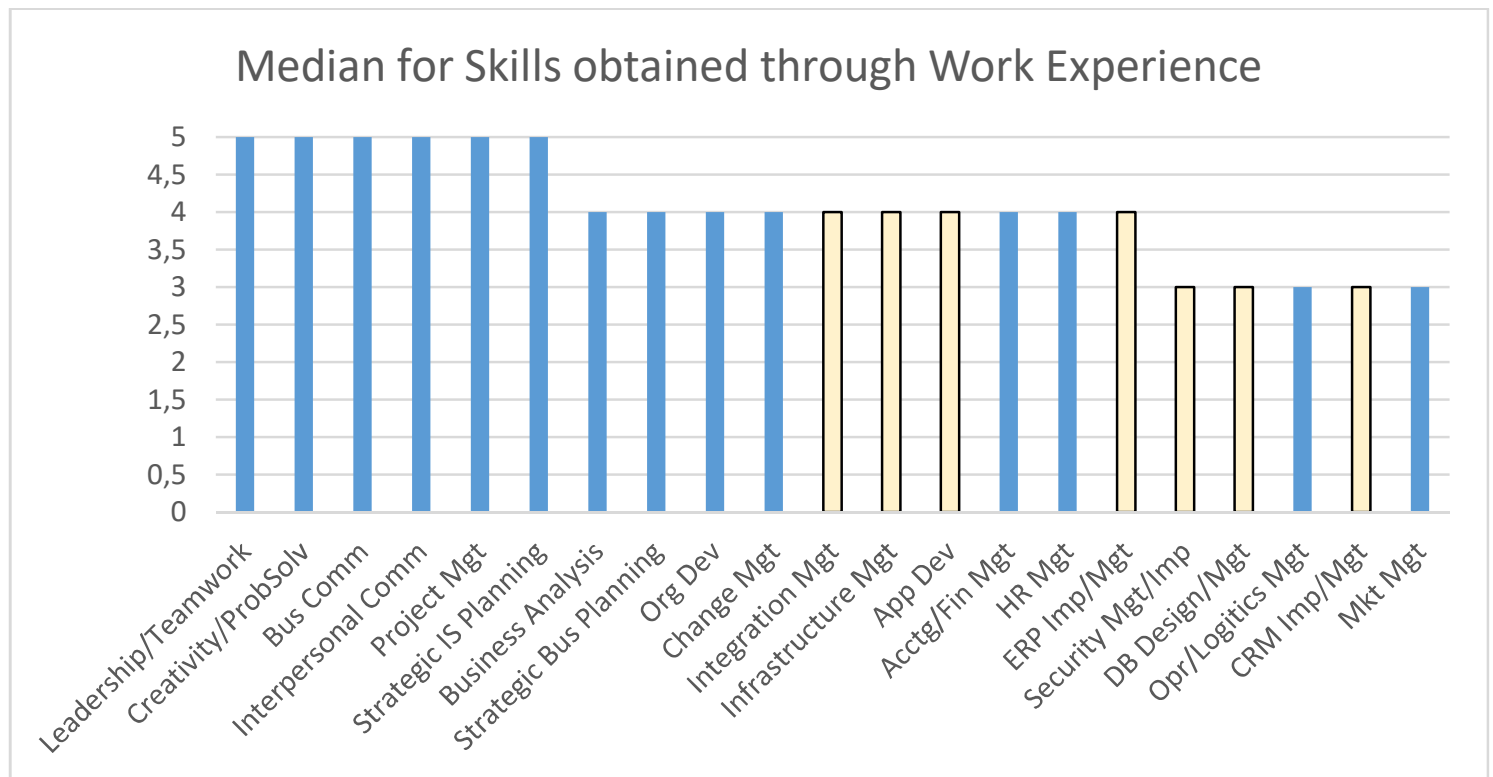

Figure 4. Median for Skills obtained through Work Experience

\section{The Single Most Important Skill for the CIO Role}

The skill rated as the most important to the CIO role were: leadership/teamwork (40\%); strategic IS planning (17\%); strategic business planning (11\%); creativity/problem solving (8\%); interpersonal communication (5\%); change management (4\%); business communication (3\%); and organizational development (3\%). All of the computing skills were $2 \%$ or lower in importance. Clearly, when asked to rank the importance of each area to their position, CIOs report leadership and managerial skills as much more important that technical skills.

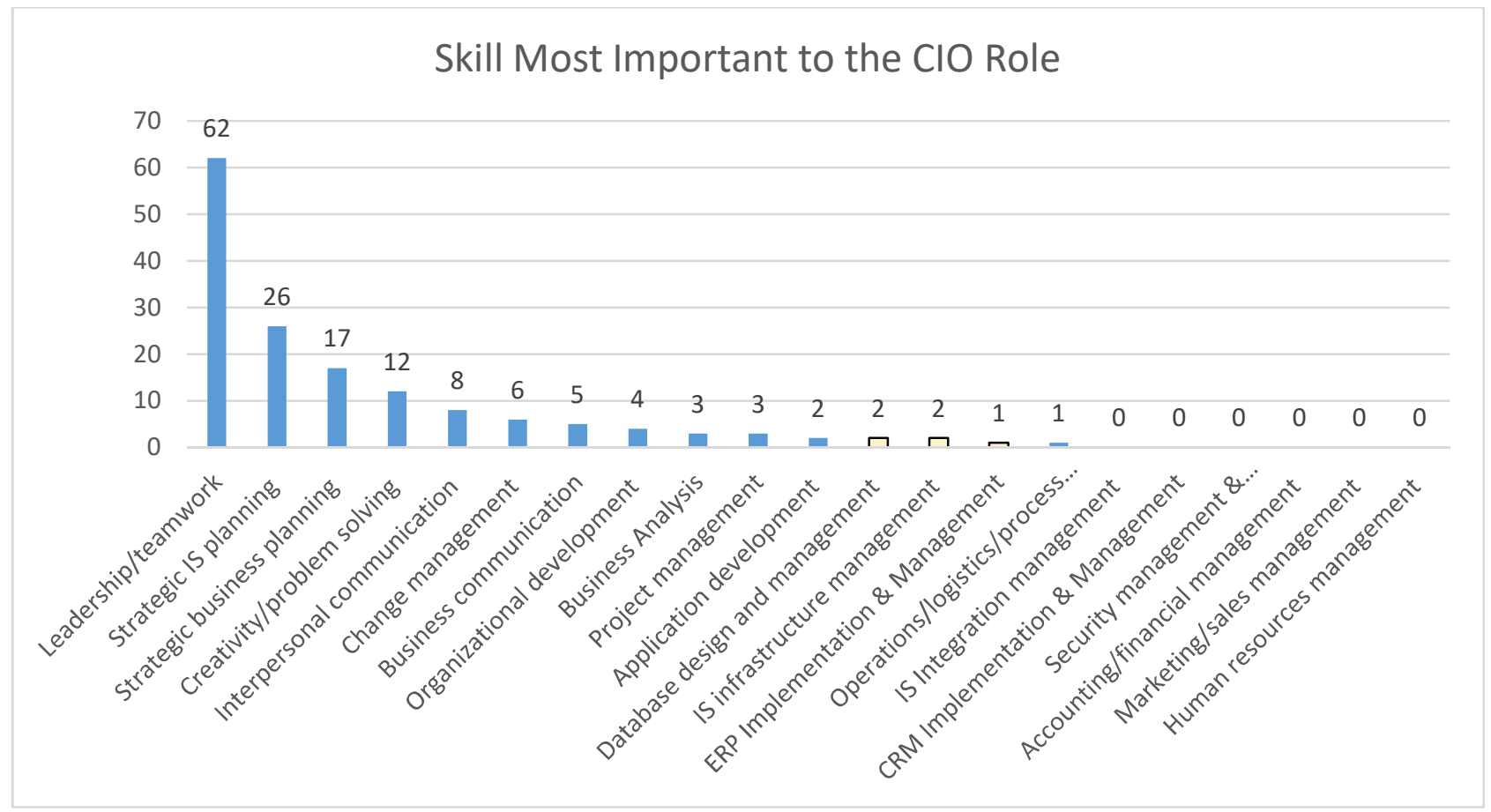

Figure 5. Skill Most Important to the CIO Role 


\section{Issues in Information Systems \\ Volume 18, Issue 1, pp. 31-43, 2017}

\section{DISCUSSION}

There are at least three distinct sets of findings that are interesting in this research. The first of these involves CIOs' rating of the importance of each of the skills we studied. The second relates to how CIOs obtain their skills, and the third examines the differences in how the CIOs rate each of the skills in contrast with their own level of experience in each area.

\section{Importance of the Skills}

Our results show that there are three distinct clusters of skills rated by importance.

\author{
Cluster 1: Extensive \\ leadership/teamwork \\ business communication \\ interpersonal communication \\ strategic IS planning \\ creativity/problem solving
}

\author{
Cluster 2: Extensive-Moderate \\ organizational development \\ business analysis \\ strategic business planning \\ project management \\ change management \\ integration management \\ accounting/financial \\ management
}

\author{
Cluster 3: Moderate \\ human resource management \\ security \\ management/implementation \\ infrastructure management \\ ERP \\ implementation/management \\ application development \\ operations/logistics management \\ CRM \\ implementation/management \\ marketing management \\ database design/management
}

Cluster 1 contains the highest rated skills and is focused on non-technical management skills. In particular, this cluster contains leadership/teamwork, both business and interpersonal communication, strategic IS planning, and creativity/problem solving. The fact that the skills in this cluster rank higher than the other two clusters is consistent with the findings of the recent literature on the CIO, which highlights the need for the CIO to exhibit leadership, vision, team-building skills, strategy-making, and diplomacy.

Likewise, the items in cluster 2 focus almost exclusively on skills needed to be an effective business manager. The only exception to this would be integration management. The skills in this cluster are rated less important than the skills in cluster 1 , but more important than the skills in cluster 3 . The fact that business management skills are more important than the technical skills is also consistent with the view from the literature that CIOs should be more business focused than technology focused.

The remaining skills form cluster 3 . These skills are all rated as moderately important by the CIOs we surveyed. The skills in this cluster are focused on two distinct areas. The first of these areas is our set of technical skills. As discussed with both of the first two clusters; it is interesting, albeit consistent with the literature, that all but one of the technical skills we assessed fall in this cluster.

The second area of skills in the third cluster relate to business management items that are specific to a particular business disciple These skills include human resource management, operations/logistics management, and marketing management. Since these business activities are most likely carried out by executives in other business functions, it is not surprising that CIOs rate the relative importance of each lower than the other skills.

The key finding related to the level of importance that the CIOs place on each skill is that CIOs value leadership and managerial skills over technical skills or management skills attributable to other functional areas. While this is not surprising when examined in the light of the prior research on CIOs, this finding does inform how individuals who aspire to become CIO should view their own career path. While a threshold level of technical skills may be important for a CIO, these skills are not the most important that a CIO should cultivate. This finding should also inform those who design graduate information systems programs. Often these programs are designed around providing students with specific technical expertise. These programs should also offer training in leadership, communication, and general business management areas as well. 


\section{Issues in Information Systems \\ Volume 18, Issue 1, pp. 31-43, 2017}

\section{Where CIOs obtain their Skill Sets}

The CIO is generally the most senior IS executive in their organization. As such, those who become CIO generally have a combination of higher education credentials and significant work experience. We asked CIOs to rate the extent to which they obtained skills in each of the areas in the study as part of their education and work experience. Recognizing that skills would be developed either through education or work experience, we asked the CIOs to rate each separately. Therefore, a CIO could rate that they obtain a skill extensively as a student and from their work experience.

CIOs obtained these skills primarily from prior-job experience as can be seen by the parallel nature of the lines in figure 6. Figure 6 includes the CIO ratings of the importance of each skill, the extent to which each skill was obtained from prior work experience, the extent each skill was obtained as part of their education, and the level of experience the CIOs had with each skill.

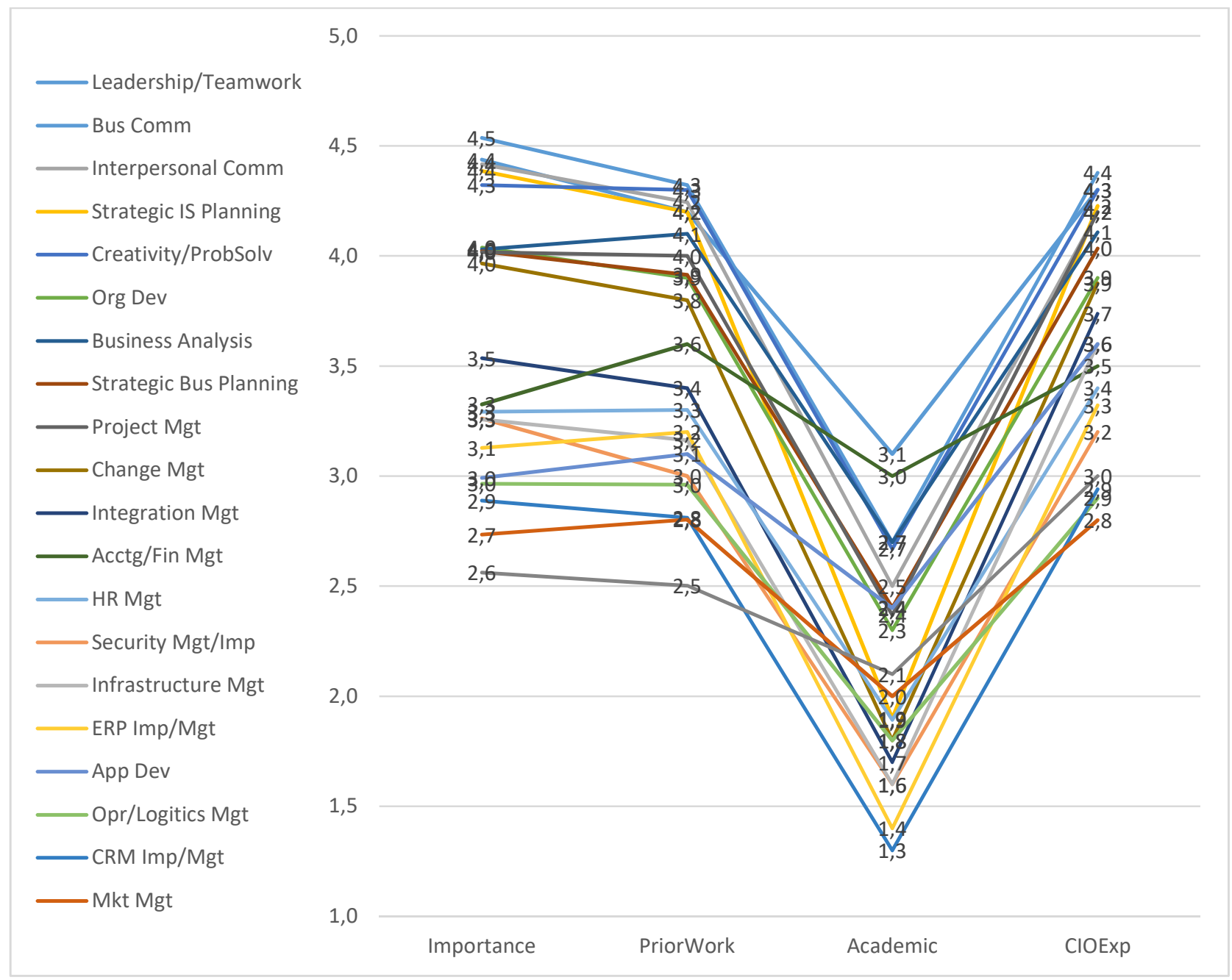

Figure 6. CIO Skills: Importance, Prior Work, Academic, CIO Experience

CIOs obtained the skills necessary for CIO work to lesser extent through academic training, and not in alignment with the importance of CIO role skills. The slope graph or bump chart below shows the movement of the skills ratings at the various dimensions of importance, prior work experience, academic training, and CIO work experience. Of note is that there is the scale shift downward in the academic training ratings. While the technical training CIOs receive as part of their education is important, it seems clear that most skills are developed on the job. 


\section{Issues in Information Systems \\ Volume 18, Issue 1, pp. 31-43, 2017}

\section{Examining the Importance of Skills Against CIO Experience}

CIOs obtained the skills necessary for CIO work through on the job CIO work, although some of the skills used are out of alignment with the importance of CIO role skills. Figure 7 examine the relationship between the rated importance of each skill and CIO level of experience in each area. It is interesting to note the difference in skill importance and CIO experience in each area. Skills that have higher levels of CIO experience, but that were rated less important than CIO experience in that area were: Application development and database design/management moved down 4 positions. Creativity/problem solving and Infrastructure management moved down 2 positions. ERP implementation/management also moved down a position in importance. Strategic IS Planning, Interpersonal Communication and Security Management all moved up a position.

$$
\begin{aligned}
& - \text { - Leadership/Teamwork } \\
& - \text { - Bus Comm } \\
& - \text { - Interpersonal Comm } \\
& - \text { - Strategic IS Planning } \\
& - \text { - Creativity/ProbSolv } \\
& - \text { - Org Dev } \\
& - \text { - Business Analysis } \\
& - \text { - Strategic Bus Planning } \\
& - \text { - Project Mgt } \\
& - \text { - Change Mgt } \\
& - \text { - Integration Mgt } \\
& - \text {-Acctg/Fin Mgt } \\
& - \text { - HR Mgt } \\
& - \text { - Security Mgt/Imp } \\
& - \text { - Infrastructure Mgt } \\
& - \text { - ERP Imp/Mgt } \\
& - \text {-App Dev } \\
& - \text { - Opr/Logitics Mgt } \\
& - \text { - CRM Imp/Mgt } \\
& - \text { - Mkt Mgt } \\
& - \text { - DB Design/Mgt }
\end{aligned}
$$

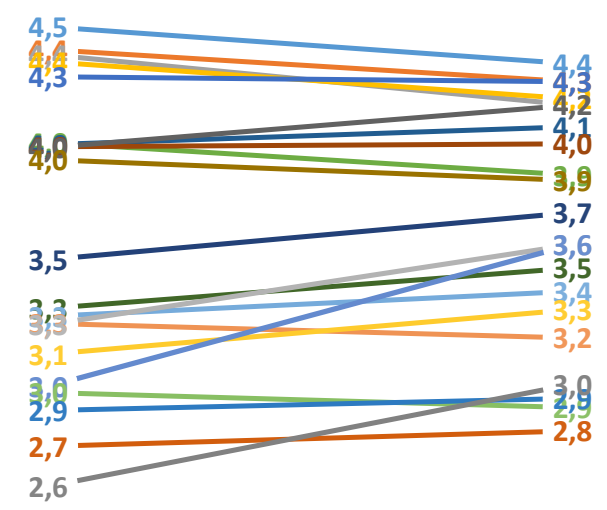

Importance

CIOExp

Figure 7. Skill importance vs CIO Work Experience

This suggests a disconnect between the experience that CIOs bring the the job and the skills needed to to be a CIO. The fact that many of the skills that appear to be out of alignment are more technical in nature may suggest that CIOs actually have more technical experience than is necessary for their job. Given that the career path to becoming CIO often includes lower level positions within the IS function that require more technical expertise for that area, this is not surprising.

There are at least two natural next steps that follow from this research. First, we did not examine the performance of any of the CIOs in our study. It would be interesting to determine if CIOs from managerial backgrounds were also more successful than those from technical backgrounds.

A second interesting line of research would examine if industry or firm characteristics determine the nature of the CIO position. Are firms in more technical or information intensive industries more likely to hire CIOs with a technical background than those in less technical or information intensive industries? This research could uncover reasons why companies have a CIO from a more technical background. 


\section{Issues in Information Systems \\ Volume 18, Issue 1, pp. 31-43, 2017}

\section{CONCLUSION}

In this paper we examine the skills individuals need for becoming CIO. First we discussed the importance of each skill to the CIO role. Specifically, we find that the skills can be clustered into three groups based on their importance. The cluster with the highest rated skills contain those skills related to strategic management, leadership, and communication. The skills in the second cluster are those related to business management. The final cluster, those with the lowest importance rankings, include those skills related to the more technical aspects of managing information systems. While this is not surprising in light of recent research on the CIO function, it does inform those who wish to become CIO. It also informs the design of graduate IS programs. Programs should include, perhaps focus on, providing strategic leadership, communication, and leadership skills in their graduates. This is somewhat out of step with our informal observations of graduate IS programs. Future research is necessary to determine if graduate IS programs are indeed out of step with the needs of their graduates.

After examining the importance of each skill sets, we discuss the degree to which each skill is obtained through prior work experience or educational background. Not surprisingly, we find that work experience both prior to and after becoming CIO is the most important source of CIO skills. It is difficult to determine if the relatively low ratings for education background in creating CIO skills is because education plays only a small role in building the skills CIOs need or because educational programs are currently focused on creating less important skills. While we don't expect that education will ever become the most important source for those skills needed for success as the most senior executive of the IS function, we do believe that education should have a role in starting individuals on this path. Future research can also examine how educational programs can best be designed to support the career paths of those who wish to become CIO.

\section{REFERENCES}

Allison, D. H. (2010). The future CIO: critical skills and competencies" (Research Bulletin 15, 2010), Boulder, CO: EDUCAUSE Center for Analysis and Research, 2010. Available: http://www.educause.edu/ecar.

Benjamin, R. I., Dickinson, C., \& Rockart, J. F. (1985). Changing Role of the Corporate Information Systems Officer, MIS Quarterly, 9(3), 177-188.

Blaskovich, J. \& Mintchik, N. (2011). Accounting executives and IT outsourcing recommendations: an experimental study of the effect of skills and institutional isomorphism. Journal of Information Technology, 26(2), 139152 .

Grover, V. (1993). The chief information officer: A study of managerial roles. Journal of Management Information Systems, 10(2), 107-130.

Hutter, A. \& Riedl, R. (2017). Chief Information Officer Role Effectiveness: Literature Review and Implications for Research and Practice. Springer International Publishing

Hunter, G. (2010). The Chief Information Officer: A Review of the Role. Journal of Information, Information Technology \& Organizations, 5, 125-143.

Ives, B. \& Olson, M. (1981). Manager of Technician? The Nature of the Information Systems Manager's Job. MIS Quarterly, 5(4), 49-63.

Karlsen, J. T., Gottschalk, P., \& Andersen, E. S. (2002). Information Technology Management Roles: A Comparison of IT Executives and IT Project Managers. Proceedings of the 35th Hawaii International Conference on System Sciences. Available: http://ieeexplore.ieee.org/document/994371/

Peppard, J. (2010). Unlocking the Performance of the Chief Information Officer. California Management Review, 52(4), 73-99. 


\section{Issues in Information Systems \\ Volume 18, Issue 1, pp. 31-43, 2017}

Sojer, M., Schläger, C., \& Locher, C. (2006). The CIO - hype, science and reality. Proceedings of the European Conference on Information Systems, 46. Available: http://aisel.aisnet.org/ecis2006

Spitze, J. \& Lee, J. (2012). The Renaissance CIO Project: The Invisible Factors of Extraordinary Success. California Management Review, 54(2), 72-91.

Stephens, C., Ledbetter, W., Mitra, A., \& Ford, N. (1992). Executive or Functional Manager? The Nature of the CIO's Job. MIS Quarterly, 16(4), 449-467. 